\title{
Reminiscence theories and postrest decrements
}

\author{
KELLY J. BLACK and R. B. PAYNE \\ University of Georgia, Athens, Georgia
}

\begin{abstract}
Inhibition and consolidation theories of psychomotor reminiscence were compared in terms of their forecasts of decremental trends in performance following variable amounts of rest. In accord with inhibition theory, but not with consolidation theory, the rest-group linear trends converged as a function of postrest practice. Although support for inhibition theory appeared somewhat weakened by the absence of significant quadratic trends, this absence can be accounted for by individual variation in the length of the warm-up phase of postrest practice. Finally, measures of temporary work decrement dissipated across rest (Ammons's $D_{w_{t}}, 1947 \mathrm{a}$ ) behaved much like conventional reminiscence measures as a function of sex and amount of rest.
\end{abstract}

For nearly four decades it has been popular to explain psychomotor reminiscence by assuming that rest permits the spontaneous dissipation of a response-produced inhibitory state known variously as temporary work decrement (Ammons, 1947a) or reactive inhibition (Hull, 1943, 1952; Kimble, 1949). About a decade ago, however, this explanation was seriously challenged by the consolidation theory of Eysenck and Frith (1977). According to this theory, reminiscence occurs because rest promotes a perseverative process in which the memory traces formed in practice are consolidated and strengthened. This process is thought to be task specific in the sense that practice on dissimilar tasks does not interfere with it, and it is also thought to pass through several stages in which learning becomes progressively more available to support performance and progressively more resistant to destruction by subsequent performance. Thus, consolidation theory can be regarded as a learning theory of reminiscence, whereas inhibition theory is properly regarded as a performance theory.

Several studies from our laboratory have called into question one or more principles of consolidation theory while upholding one or more principles of inhibition theory. With regard to the task-specificity principle, Hsu and Payne (1979) and Huang and Payne (1977) showed that reminiscence in a mirror tracking task was virtually eliminated when the intertrial intervals (ITIs) were filled by practice on a rotary pursuit task, less so when the interval was less filled (Coppage \& Payne, 1981). These results seemed to negate the task-specificity principle of consolidation theory and to support the negative-drive principle of reactive inhibition theory; however, Frith and Eysenck (1981) disparaged the use of mirror tracking to test their theory on the grounds that it did not involve the same kind of learning as did the rotary pursuit task on which their theory was based. As Payne (1981) and Wild and Payne (1983) noted, however, this argument sharply limited the generality of the theory, and it presupposed what is basi-

Send reprint requests to R. B. Payne, Department of Psychology, University of Georgia, Athens, GA 30602. cally under dispute, namely that reminiscence is a learning phenomenon rather than a performance phenomenon.

More recent studies have focused on the contention that the consolidative process increases the resistance of learning to destruction by subsequent performance. Dietrich and Payne (1986) varied consolidative opportunities by giving their subjects several trials on rotary tracking under various ITI conditions, and then switching the subjects abruptly to massed practice for several additional trials. Assuming that consolidative principles are operating in this situation, the rate of performance decrement during the massed trials should be an inverse function of the duration of the prior ITIs, that is, the more fully consolidated the learning is at the end of the spaced sequence, the less rapidly it should be diminished by the massed sequence. On the other hand, inhibition principles predict that longer ITIs during the earlier trials would lead to more precipitous decrements during the massed trials because the longer the ITI during the distributed trials, the more inhibition-free the subjects should be at the outset of the massed trials, and hence the more rapidly they should accumulate inhibition in accordance with the implied negatively accelerated character of the accumulation function (Hull, 1952). Suffice it to say that the results were fully in accord with inhibition theory.

Using a somewhat different approach, Ball and Payne (1987) varied consolidative opportunities by giving their subjects 15,30 , or 45 trials on rotary tracking with ITIs of $40 \mathrm{sec}$, and then switched them abruptly to massed practice for several more trials. Under these conditions, consolidation theory implies that the rate of performance decrement during the massed trials should be related inversely to the number of distributed trials, whereas inhibition theory implies that the rate of decrement should be essentially independent of the number of distributed trials because all subjects are virtually inhibition-free at the outset of the massed trials, and hence are comparably susceptible to the accumulation of inhibition. Once again, the results were fully in accord with inhibition theory.

The present study compared the two theories in a situation in which the duration of the rest interval between 
two segments of massed practice was varied. On grounds previously noted (Dietrich \& Payne, 1986), consolidation theory predicts that the rate of performance decrement during the postrest trials will be related inversely to the duration of the rest interval, whereas inhibition theory predicts that the rate of decline will be an increasing function of the duration of the interval.

\section{METHOD}

\section{Subjects}

The experimental sample consisted of 80 volunteer subjects, 40 of each sex, from introductory psychology classes at the University of Georgia. The subjects were awarded course credit points for participation. All were Caucasian, visually competent, and right-handed as inferred from self-classification and writing custom. Ages ranged from 18 to 22 years.

\section{Task}

A copy of the United States Air Force SAM Rotary Pursuit Test (Model CM803B2), as described by Melton (1947), served as the experimental task. This task required the subjects to track a round silver target, $19 \mathrm{~mm}$ in diameter, as it rotated clockwise at $60 \mathrm{rpm}$. Time on target was recorded to the nearest $.01 \mathrm{sec}$ for each 30 -sec period of practice.

\section{Procedure}

The 80 subjects were assigned randomly to rest groups of $0,2,4$, or $6 \mathrm{~min}$, with the constraint that each group contain 10 males and 10 females. After instruction and demonstration, all subjects practiced continuously for 1030 -sec trials, rested for their assigned durations, and then practiced continuously for 1230 -sec trials. While resting, the 2-, 4-, and 6-min subjects were seated until the last $10 \mathrm{sec}$ of their rest periods, whereupon they resumed standing positions in front of the apparatus and placed the stylus on the target. A buzzer was sounded $2 \mathrm{sec}$ before the target began to rotate.

\section{RESULTS}

\section{Postrest Trends}

The analysis of the postrest trends was conditioned by three features of the data that should be noted here. First,

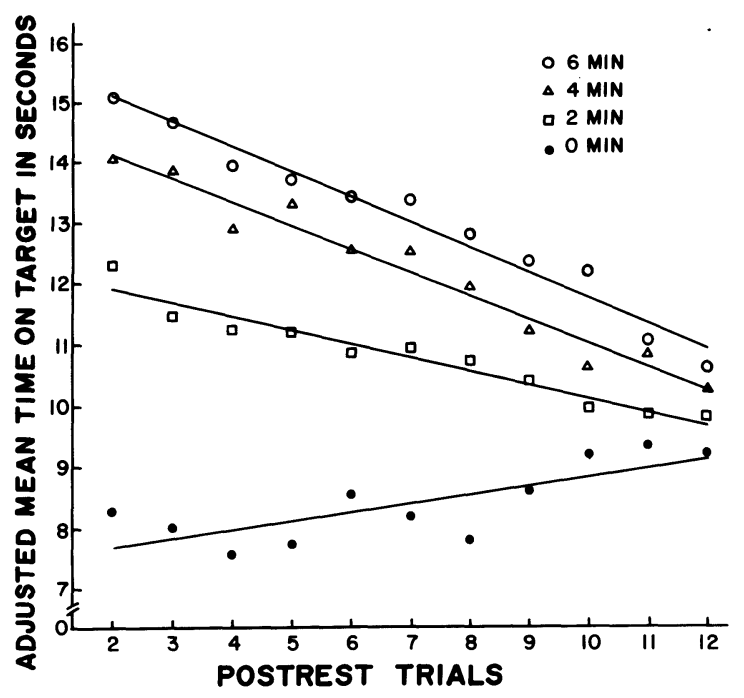

Figure 1. Adjusted mean time on target as a function of practice and amount of prior rest. Linear functions were fitted by the method of least squares.

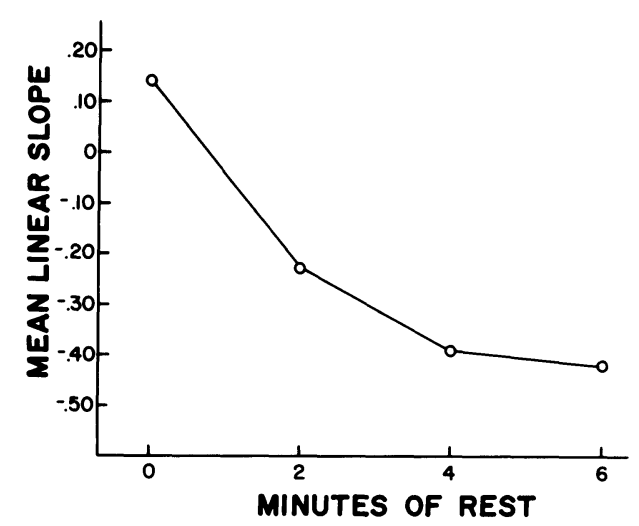

Figure 2. Mean linear postrest slope as a function of amount of prior rest.

although the prerest practice conditions were the same for all subjects, males significantly outperformed females on the prerest trials, as expected (Noble, 1978). Second, despite the uniformity of prerest conditions, there was a considerable amount of sampling variation among the prerest means of the rest groups within sexes. Third, as Ammons (1947a) and Eysenck and Frith (1977) noted, postrest upswing (often called "warm-up") was evident in the 4- and 6-min groups, for whom average performance peaked on Trial 2. Inasmuch as Eysenck and Frith regard postrest upswing as falling outside the boundaries of consolidation theory and as related to "a rather different body of evidence" (p. 344), we omitted the scores of Trial 1 from the analysis of postrest trends. Taken altogether, the foregoing circumstances led us to adjust the remaining postrest scores within sexes for regression upon mean prerest scores, and then to subject the adjusted scores to a variance analysis in which sex and rest conditions provided the main between-subjects effects and practice (trials) provided the main within-subjects effect. These manipulations were followed by orthogonal polynomial analyses of between- and within-subjects trends.

The outcomes were simple and straightforward. Males performed significantly better than females, as expected $[F(1,71)=55.77, p<.001]$, and this effect was orthogonal to rest and practice effects. The variation associated with rest treatments was significant $[F(3,71)=$ $19.03, p<.001$ ], $95 \%$ of which was due to a positive linear relationship between mean score and amount of rest $\left[F_{\text {lin }}(1,71)=54.27, p<.001\right]$. However, the interaction of rest and practice effects was also significant $[F(30,720)$ $=4.82, p<.001]$. Shown in Figure 1, the bulk of this variation (89\%) was accounted for by the convergence of linear trends across practice $\left[F_{\text {lin }}(1,72)=15.84\right.$, $p<.001$ ], with no significant trend variance remaining. As shown in Figure 2, the slopes of these convergent trends were $.143(0 \mathrm{~min}),-.227(2 \mathrm{~min}),-.391$ (4 min), and -.417 (6 $\mathrm{min})$. An analysis of the 80 individual slopes showed that both the linear $\left[F_{\text {lin }}(1,72)=40.45\right.$, $p<.001]$ and quadratic $\left[F_{\text {quad }}(1,72)=7.03, p<.01\right]$ trends of this function were significant. Thus, the slope 
of the postrest trend became increasingly negative as rest increased.

\section{Reminiscence}

The presence of postrest upswing suggested that Ammons's (1947a) method of correcting for warm-up decrement would be more suitably applied here than the conventional method of measuring classical reminiscence. Accordingly, individual linear functions were fitted to the postrest scores of Trials 2-12, and the intercepts of these functions were taken as expected scores on Trial 1 had there been no need to warm up. Corresponding mean scores on the prerest trials were subtracted from the intercepts to index what Ammons (1947a) called the amount of temporary work decrement dissipated during rest $\left(D_{w_{t}}\right)$. Within each sex, these values were then reduced by the average practice gain of the 0 -min group in order to quantify truly rest-dependent gains.

Mean gains as a function of sex and rest are shown in Figure 3. One can see that the gain increased as a negatively accelerated function of rest $\left[F_{\text {lin }}(1,72)=94.57\right.$, $\left.p<.001 ; F_{\text {quad }}(1,72)=7.39, p<.01\right]$, as often reported (Ammons, 1947b; Irion, 1949; Kimble \& Horenstein, 1948). Moreover, females outgained males $[F(1,72)$ $=5.36, p<.025]$, as Huang and Payne found (1975). There was also some tendency for female gains to increase more rapidly than male gains as a function of rest $\left[F_{\text {lin }}(1,72)=2.91, p=.09\right]$, as shown more rigorously by McBride and Payne $(1979,1980)$. Thus, these measures behaved much like conventional reminiscence measures as a function of sex and rest variables.

\section{DISCUSSION}

The main question at issue was whether obtained postrest downswing trends were more realistically foreseen by one theory than by the other. Inasmuch as the linear slopes became increasingly negative as rest increased, it is clear that expectations based on cotisolidation theory were

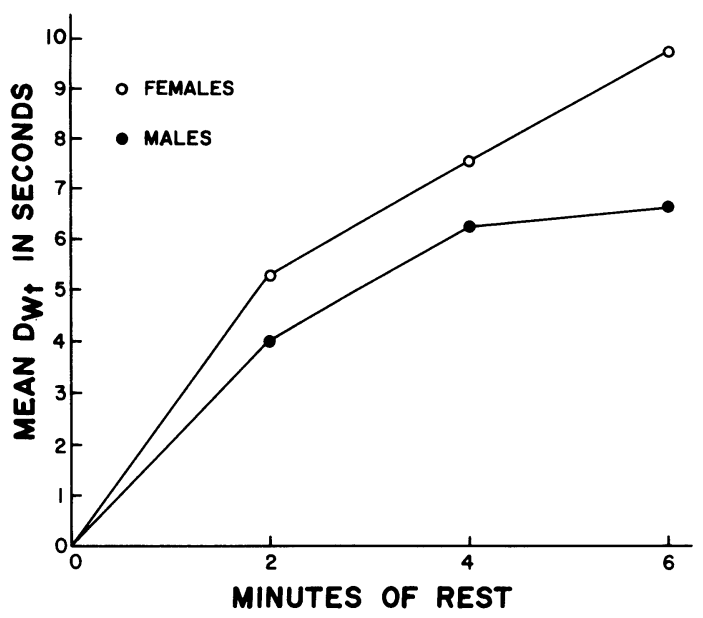

Figure 3. Mean temporary work decrement dissipated $\left(\mathrm{D}_{\mathrm{w}_{t}}\right)$ as a function of sex and amount of rest. not realized. To this extent at least, our findings were concordant with those of Dietrich and Payne (1986) and Ball and Payne (1987). Although the results provided stronger support for inhibition theory than for consolidation theory, this support seemed, superficially at least, to be somewhat weakened by the fact that the quadratic component of these trends was not statistically significant. If inhibition accumulates in a negatively accelerated fashion, as implied by Hull (1952), then postrest downswing should also be negatively accelerated, as it is usually found to be. Moreover, the quadratic slopes of the more rested subjects should be steeper than those of the less rested subjects. It is believed that these expectations were not supported in the present study because the quadratic trends were obscured by individual variation in the ordinal position of the trial on which the maximum postrest score occurred (i.e. variation in the length of the warm-up phase). If so, the absence of significant quadratic trends does not necessarily reflect a failure of inhibition theory; it can be viewed instead as a consequence of uncontrolled interaction of warm-up and decremental processes.

With regard to the analysis of temporary work decrement dissipated across rest, the results were in substantial accord with those for which inhibition theory has been successfully invoked to account for the effects of sex and rest variables on conventional reminiscence measures (McBride \& Payne, 1979, 1980; Shaffer \& Payne, 1982).

\section{REFERENCES}

Ammons, R. B. (1947a). Acquisition of motor skill: I. Quantitative analysis and theoretical formulation. Psychological Review, 54, 263-281.

Ammons, R. B. (1947b). Acquisition of motor skill: II. Rotary pursuit performance with continuous practice before and after a single rest. Journal of Experimental Psychology, 37, 393-411.

BAll, L. J., \& PAYNE, R. B. (1987). A comparison of inhibition and consolidation theories of spaced practice effects. Manuscript submitted for publication.

Coppage, S. J., \& Payne, R. B. (1981). An experimental test of current theories of psychomotor reminiscence. Perceptual \& Motor Skills, 52, 343-352.

Dietrich, J. M., \& Payne, R. B. (1986) An experimental test of inhibition and consolidation theories of spaced practice effects. Perceptual \& Motor Skills, 63, 1051-1057.

EYSENCK, H. J., \& FRITH, C. D (1977). Reminiscence, motivation, and personality. New York: Plenum Press.

FrITH, C. D., \& EYSENCK, H. J. (1981). Reminiscence-psychomotor learning: A reply to Coppage and Payne. Perceptual \& Motor Skills, 53,842 .

Hsu, S. H., \& PAYNe, R. B. (1979). Effector localization and transfer of reactive inhibition. Journal of Motor Behavior, 11, 153-158.

HuANG, K. L., \& PAYNE, R. B. (1975). Individual and sex differences in reminiscence. Memory \& Cognition, 3, 252-256.

Huang, K. L., \& Payne, R. B. (1977). Transfer of reactive inhibition. Journal of Motor Behavior, 9, 293-300.

Hull, C. L. (1943). Principles of behavior. New York: AppletonCentury-Crofts.

Hull, C. L. (1952). A behavior system. New Haven: Yale University Press.

IRION, A. L. (1949). Reminiscence in pursuit-rotor learning as a function of length of rest and of amount of pre-rest practice. Journal of Experimental Psychology, 39, 492-499.

Kimble, G. A. (1949). An experimental test of a two-factor theory of inhibition. Journal of Experimental Psychology, 39, 15-23.

Kimble, G. A., \& Horenstein, B. R. (1948). Reminiscence in motor learning as a function of length of interpolated rest. Journal of Experimental Psychology, 38, 239-244.

McBride, D. K., \& PAYNe, R. B. (1979). Psychomotor reminiscence as a function of sex and length of rest period. Journal of Motor Behavior, 11, 59-64.

McBride, D. K., \& PAYNE, R. B. (1980). The sex difference in rotary pursuit performance: Aptitude or inhibition? Journal of Motor Behavior, 12, 270-280. 
Melton, A. W. (Ed.). (1947). Apparatus tests (AAF Aviation Psychology Program, Research Report No. 4). Washington, DC: U.S. Government Printing Office.

NoBle, C. E. (1978). Age, race, and sex in the learning and performance of psychomotor skills. In R. T. Osborne, C. E. Noble, \& N. Weyl (Eds.), Human variation: The biopsychology of age, race, and sex. New York: Academic Press.

PAYNe, R. B. (1981). Reminiscence theory: A reply to Frith and Eysenck. Perceptual \& Motor Skills, 53, 869-870.
Shaffer, G. S., \& PAYNe, R. B. (1982). Contralateral transfer of reactive inhibition as a function of sex and interpolated rest. Perceptual \& Motor Skills, 54, 979-985.

Wild, H. M., \& PAYNe, R. B. (1983). An experimental test of two theories of spaced practice effects. Perceptual \& Motor Skills, 56, 267-274.

(Manuscript received for publication April 13, 1987.) 